\title{
Controls of carbon dioxide concentrations and fluxes above central London
}

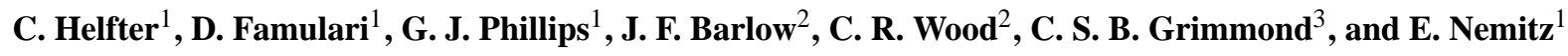 \\ ${ }^{1}$ Centre for Ecology and Hydrology (Edinburgh Research Station), Penicuik, EH26 0QB, UK \\ ${ }^{2}$ Department of Meteorology,University of Reading, Reading, RG6 6BB, UK \\ ${ }^{3}$ Department of Geography, King's College London, London, UK
}

Received: 25 August 2010 - Published in Atmos. Chem. Phys. Discuss.: 12 October 2010

Revised: 17 February 2011 - Accepted: 18 February 2011 - Published: 2 March 2011

\begin{abstract}
Eddy-covariance measurements of carbon dioxide fluxes were taken continuously between October 2006 and May 2008 at $190 \mathrm{~m}$ height in central London (UK) to quantify emissions and study their controls. Inner London, with a population of 8.2 million $\left(\sim 5000\right.$ inhabitants per $\left.\mathrm{km}^{2}\right)$ is heavily built up with $8 \%$ vegetation cover within the central boroughs. $\mathrm{CO}_{2}$ emissions were found to be mainly controlled by fossil fuel combustion (e.g. traffic, commercial and domestic heating). The measurement period allowed investigation of both diurnal patterns and seasonal trends. Diurnal averages of $\mathrm{CO}_{2}$ fluxes were found to be correlated with traffic but also exhibited an inverse dependency on atmospheric stability in the near-neutral range, with higher fluxes coinciding with unstable stratification during most seasons and perhaps reflecting how changes in heating-related natural gas consumption and, to a lesser extent, photosynthetic activity controlled the seasonal variability. Despite measurements being taken at ca. 22 times the mean building height, coupling with street level was adequate, especially during daytime. Night-time saw a higher occurrence of stable or neutral stratification, especially in autumn and winter, which resulted in data loss in post-processing and caused the tower to become decoupled from street level. $\mathrm{CO}_{2}$ fluxes observed at night were not always correlated with traffic counts, probably reflecting this decoupling, but also the fact that at night heating was always a larger source than traffic. No significant difference was found between the annual estimate of net exchange of $\mathrm{CO}_{2}$ for the expected measurement footprint and the values derived from the National Atmospheric Emissions Inventory (NAEI), with daytime fluxes differing by only $3 \%$. This agreement with NAEI data also supported the use of the simple flux footprint model which was applied to the London
\end{abstract}

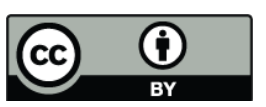

Correspondence to: C. Helfter (caro2@ceh.ac.uk) site; this also suggests that individual roughness elements did not significantly affect the measurements due to the large ratio of measurement height to mean building height.

\section{Introduction}

In recent years, monitoring of carbon dioxide $\left(\mathrm{CO}_{2}\right)$ exchange with natural and semi-natural environments has benefited from communication through international flux networks (FLUXNET and its regional components such as CarboEurope, AmeriFlux, AsiaFlux, etc.). Within some of these communities considerable effort has been made to standardise measurement techniques and data processing methods (Aubinet et al., 2000; Foken et al., 2004; Moncrieff et al., 2004). Databases with long-term micrometeorological data, heat and trace gas fluxes for sites on five continents have been set up. These span latitudes from $30^{\circ} \mathrm{S}$ to $70^{\circ} \mathrm{N}$ and encompass boreal, temperate and tropical forests, wetlands, crops and tundra vegetation types (Baldocchi et al., 2001). In contrast, relatively few measurements of $\mathrm{CO}_{2}$ exchange have been performed in urban environments, where over $50 \%$ of the world's population are estimated to live (United Nations, $2007)^{1}$, and the majority of studies were conducted in temperate areas of the Northern hemisphere, e.g. Basel, Switzerland (Vogt et al., 2006); Chicago, USA (Grimmond et al., 2002); Edinburgh, UK (Nemitz et al., 2002); Tokyo, Japan (Moriwaki and Kanda, 2004), as compiled in the database of the International Association for Urban Climate ${ }^{2}$. Although these studies vary in length, all found that the urban environment was a net source of $\mathrm{CO}_{2}$. Summer fluxes in Tokyo were comparable to those measured in Chicago

\footnotetext{
${ }^{1}$ http://unstats.un.org/unsd/demographic/products/dyb/dyb2. htm

${ }^{2}$ http://www.urban-climate.org
}

Published by Copernicus Publications on behalf of the European Geosciences Union. 
and approximately half of mean Basel values. Values observed in central Edinburgh were the largest of all (e.g. four times Chicago values and twice Basel values) reflecting the strength of $\mathrm{CO}_{2}$ sources found in the footprint of the very central measurement location. Seasonal variations are important as demonstrated for example in Tokyo, where wintertime fluxes were more than twice their summertime counterparts due to changes in the demand for fossil fuels for domestic and commercial heating as well as photosynthetic activity. Despite a recent surge in publications pertaining to emissions from urban environments, data remains sparse compared to the natural environment.

As a consequence of this data shortage, while large anthropogenic point sources are relatively-well characterised, emissions from diffuse area sources and their variability in space and time are less-well represented in bottom-up emissions inventories. As many countries are pledging large percentage cuts in greenhouse gas emissions, the monitoring of trace gas emissions through flux measurements at the urban neighbourhood or local scale becomes an attractive and important approach to evaluating the success in reaching emission targets and to identify potential underestimated sources.

Published urban $\mathrm{CO}_{2}$ exchange studies vary in length, from a few weeks (Velasco et al., 2005) to several months (Vesala et al., 2008) to a few years (Soegaard and MollerJensen, 2003; Coutts et al., 2007; Crawford et al., 2011). Whilst a rather diverse range of urban environments (e.g. in terms of mean building height, vegetation cover) has been investigated, measurement heights were overall of the order of 2-3 times mean building height, i.e. near the minimum threshold above which eddy-covariance measurements can be considered to be representative of the local scale (Grimmond and Oke, 1999).

In this study, we examine the dynamics of $\mathrm{CO}_{2}$ emissions above central London (UK) based on eddy-covariance measurements taken atop a $190 \mathrm{~m}$ telecommunication tower. The instruments were located at ca. 22 times the mean building height $\left(z_{\mathrm{H}}\right)$ (Wood et al., 2009, 2010a), i.e. ca. 4-5 times larger than the ratios reported for most urban sites in the literature, and took place between October 2006 and May 2008.

Of the different pollutants, emissions of $\mathrm{CO}_{2}$ are probably best understood, because emissions are directly linked to fuel use, rather than combustion conditions and evaporation sources (as it is the case, e.g. for $\mathrm{CH}_{4}, \mathrm{~N}_{2} \mathrm{O}, \mathrm{CO}$, VOCs and aerosols) (Allan et al., 2010; Langford et al., 2010). The aim of the present study was to determine the drivers of $\mathrm{CO}_{2}$ emissions on both a diurnal and a seasonal basis and evaluate the suitability of the measurement site for the purpose of establishing robust urban budgets of $\mathrm{CO}_{2}$ and, by extension, other pollutants. Fluxes of $\mathrm{CO}, \mathrm{O}_{3}$, VOCs, aerosol number and aerosol chemical species measured at the same site during two intensive observation periods (October 2006 and October/November 2007) are presented elsewhere (Martin et al., 2009; Langford et al., 2010; Nemitz et al., 2010; Phillips et al., 2010).

\section{Methods}

\subsection{Measurement environment and instrumentation}

Fluxes of $\mathrm{CO}_{2}$ and $\mathrm{H}_{2} \mathrm{O}$ were measured continuously in central London from October 2006 until May 2008 from a $190 \mathrm{~m}$ telecommunication tower (BT Tower; $51^{\circ} 31^{\prime} 17.4^{\prime \prime} \mathrm{N}$ $0^{\circ} 8^{\prime} 20.04^{\prime \prime} \mathrm{W}$ ). Mean building height is $8.8 \pm 3.0 \mathrm{~m}$ within $1-10 \mathrm{~km}$ of the tower and $5.6 \pm 1.8 \mathrm{~m}$ for suburban London beyond this (Evans, 2009; Wood et al., 2010a). Three sites deviating substantially from the mean building height were identified within the $1-10 \mathrm{~km}$ region:

- The Regent's Park, a 197 ha green space located ca. $1 \mathrm{~km}$ north-west of the tower;

- Hyde Park, a 142 ha park whose north-east corner lies ca. $1.5 \mathrm{~km}$ south-west from the tower;

- Canary Wharf (8-10 km east-south-east of the tower), where a large number of London's tallest building are found (the tallest three buildings are 200,200, $235 \mathrm{~m}$ ). Building heights in this area range from $37 \mathrm{~m}$ to ca. $69 \mathrm{~m}$ (Evans, 2009).

The conurbation of Greater London, with 12.3 million inhabitants, extends at least $20 \mathrm{~km}$ into all directions.

The eddy-covariance system consisted of an ultrasonic anemometer (R3-50 Gill Instruments, Lymington, UK) operated at $20 \mathrm{~Hz}$ and a LI-COR 6262 infrared gas analyser (IRGA; LI-COR, Lincoln, NE, USA) fitted with an in-house auto-calibration system. Zero and $\mathrm{CO}_{2}$ span calibration using a $404 \mathrm{ppm}$ standard were scheduled to occur every $72.5 \mathrm{~h}$, gradually spreading the associated loss in measurement over the full $24 \mathrm{~h}$ cycle. Calibration pressure, which was adjusted so as to match sampling pressure as closely as possible, was recorded along with all relevant calibration parameters $\left(\mathrm{CO}_{2}\right.$ and $\mathrm{H}_{2} \mathrm{O}$ readings on zero, $\mathrm{CO}_{2}$ span value) in order to correct the $\mathrm{CO}_{2}$ and $\mathrm{H}_{2} \mathrm{O}$ concentrations $\left(\left[\mathrm{CO}_{2}\right]\right.$ and $\left.\left[\mathrm{H}_{2} \mathrm{O}\right]\right)$ during post-processing. A custom National Instruments LabView program was used to log wind and trace gas concentration data and to trigger auto-calibration events.

Air was sampled $0.3 \mathrm{~m}$ below the sensor head of the ultrasonic anemometer - which was itself mounted on a $3 \mathrm{~m}$ mast to the top of a $15 \mathrm{~m}$ lattice tower situated on the roof of the tower (instrument head at $190 \mathrm{~m}$ above street level) - and pulled down $45 \mathrm{~m}$ of $12.7 \mathrm{~mm}\left(1 / 2^{\prime \prime}\right)$ OD Teflon tubing.

In addition, meteorological variables (temperature, relative humidity, pressure, precipitation, wind speed and direction) were also measured with a multi-sensor (Weather Transmitter WXT510, Vaisala).

The traffic-activity data used in this paper were measured at the Marylebone Road traffic census site, one of the busiest urban arteries in Europe, $1.5 \mathrm{~km}$ west of the BT tower; 
this data was compared to traffic counts from four Transport for London (TfL) ${ }^{3}$ sites located in central London (Fig. S1, Supplement).

\subsection{Flux calculations, quality assurance and filtering}

Local fluxes $\left(F_{\mathrm{g}}\right)$ of trace gas $g$, calculated offline by a second custom LabView program use the core eddy-covariance equation:

$$
F_{\mathrm{g}}=\overline{w^{\prime} \chi_{g}^{\prime}}
$$

Equation (1) is the covariance between the deviation from their respective means of the vertical wind velocity component $(w)$ and of the trace gas concentration $\left(\chi_{\mathrm{g}}\right)$. The 30-min flux calculations used the time -lag corrected and despiked time series and two-dimensional co-ordinate rotation. In line with other urban flux measurement, no corrections were applied for storage and advection in relating this local flux to the surface flux.

Processed data were filtered using a three-step quality assurance algorithm whereby data were deemed of satisfactory quality if:

1. The level of turbulence was sufficient, i.e. locallyderived friction velocity $u_{*} \geq 0.2 \mathrm{~m} \mathrm{~s}^{-1}$.

2. The stationarity test described by Foken and Wichura (1996); Foken et al. (2004), which requires the flux for the complete averaging interval (here $30 \mathrm{~min}$ ) to be within $30 \%$ of the fluxes calculated for the sub-intervals $(6 \times 5 \mathrm{~min})$, was satisfied.

3. The outcome of the integral turbulence characteristics test (ITC; Foken and Wichura, 1996; Foken et al., 2004) - which compares the turbulence statistics of wind components, temperature or trace gas concentration to that of modelled values for a given stability class - was a quality class of 3 at the very maximum (i.e. with a discrepancy of $50 \%$ or less between model and measurement).

The ITC similarity relationships were determined for $w$ and $\left[\mathrm{CO}_{2}\right]$ respectively under unstable atmospheric conditions $(-6.2<\zeta<-0.05)$ using:

$$
\begin{aligned}
& \frac{\sigma_{w}}{u_{*}}=C_{1}\left(1+C_{s}|\zeta|\right)^{C_{3}} \\
& \frac{\sigma_{\mathrm{CO}_{2}}}{\chi_{*}}=C_{1}\left(1+C_{s}|\zeta|\right)^{C_{3}} \\
& \chi_{*}=\frac{-\overline{w^{\prime}\left[\mathrm{CO}_{2}\right]^{\prime}}}{u_{*}}
\end{aligned}
$$

\footnotetext{
${ }^{3}$ http://www.tfl.gov.uk/
}

where $\sigma_{i}$ is the standard deviation of quantity $i, u_{*}$ is the locally-derived friction velocity, $C_{j}(j=1,2,3)$ are parameters obtained by fitting to the entire dataset (cf. Sect. 3.2 below) and the atmospheric stability parameter $(\zeta)$ is:

$\zeta=\frac{z_{\mathrm{m}}-d}{L}$

Here $z_{\mathrm{m}}$ is the measurement height $(190 \mathrm{~m}), d$ is the zeroplane displacement length $(4.3 \pm 1.9 \mathrm{~m}$ within $10 \mathrm{~km}$ of the tower; (Wood et al., 2010a) and $L$ is the locally-derived Obukhov length.

Data were rejected due to insufficient turbulence (13\%), non-stationarity (6\%) and non-fulfilment of the ITC criterion (2\%). Combined with downtime of the measurement system, this left $54 \%$ of data coverage, equating to ca. 9500 measurement points in 2007.

\subsection{Comparison of emissions estimates with NAEI}

The official UK National Atmospheric Emissions Inventory $(\mathrm{NAEI})^{4}$ provided annual $\mathrm{CO}_{2}$ emissions estimates for 2006 at a $1 \mathrm{~km} \times 1 \mathrm{~km}$ spatial resolution in central London (Bush et al., 2008). The spatial inventory consisted of eleven $\mathrm{CO}_{2}$ emission categories, including emissions from industrial/commercial electricity and gas consumption, domestic electricity and gas consumption, diesel railways, agriculture, domestic oil and fuel usage and road traffic. Emission sources and intensities for 2006 were assumed to also be valid for 2007 , for which spatially disaggregated emissions were not yet available at the time this paper was written, and were consequently compared with emissions estimates obtained by eddy-covariance measurements of $\mathrm{CO}_{2}$ fluxes taken at the BT tower. Statistics of gas provision are available at London borough level, which vary in area. To compare activity figures with the measured fluxes, the NAEI emission information was used to estimate the flux that the NAEI implies should have been measured on the tower. For this it is necessary to estimate the contribution of the various boroughs to each 30-min flux measurements.

There are no operational footprint models for urban environments that fully account for topography and spatial variations in building height and surface heat flux. Here, as an approximation, the analytical footprint model proposed by Kormann and Meixner (2001) was applied, which accounts for non-neutral stratification but assumes homogeneous surfaces. The aerodynamic roughness length for momentum $\left(z_{0}\right)$ was estimated to be $0.87 \pm 0.48 \mathrm{~m}$ in central London (Padhra, 2009), with $1 \mathrm{~m}$ used in the present study.

Canary Wharf, which is home to some of the tallest buildings in London, has roughness length of the order of 2$2.5 \mathrm{~m}$ which differs from that in more (vertically) homogenous areas. No special treatment was however applied to Canary Wharf as the wind occurrence from that sector was low (ca. 7\% in 2007) as is its relative surface area. Furthermore,

\footnotetext{
${ }^{4}$ http://www.naei.org.uk
} 
Wood et al. (2010a) show that the Tower Hamlets borough, where Canary Wharf is located, does not contribute to flux measurements on the BT tower during unstable conditions.

The Kormann-Meixner (KM) model - which requires $z_{0}$, $u_{*}, L$ and $z_{\mathrm{m}}$ - was used to estimate the flux footprint on a half-hourly basis. A software tool coded in Microsoft Excel - described by Neftel et al. (2008) - which allows footprint contributions to be mapped to user-defined spatial elements, was used to determine the individual contributions of all 32 London boroughs to the total flux measured at the BT tower. Formally, the flux $F\left(0,0, z_{\mathrm{m}}\right)$ at measurement height $z_{\mathrm{m}}$ can be expressed as (Kormann and Meixner, 2001):

$$
F\left(0,0, z_{\mathrm{m}}\right)=\int_{-\infty}^{\infty} \int_{0}^{\infty} F(x, y, 0) \phi\left(x, y, z_{\mathrm{m}}\right) d x d y
$$

Here, the $\mathrm{x}$-axis is aligned with the average horizontal wind direction, $y$ is the crosswind coordinate and $\phi\left(x, y, z_{\mathrm{m}}\right)$ is the flux footprint (i.e. the flux portion originating from a point source of strength $F$ located at $(x, y, 0)$ and observed at $\left.\left(x, y, z_{\mathrm{m}}\right)\right)$. In practice, the integrals in Eq. (6) were replaced by a discrete sum due to the finite number of sources (boroughs):

$$
F\left(0,0, z_{\mathrm{m}}\right)=\sum_{i=1}^{N} F_{i} \phi_{i}
$$

with $F_{i}$ and $\phi_{i}$ the emissions and flux footprint of borough $i$, and $N$ the total number of boroughs within the footprint area. $\mathrm{CO}_{2}$ emissions per borough $\left(F_{i}\right)$ were obtained from the NAEI data (contributions from commercial and domestic electricity consumption were subtracted since the associated $\mathrm{CO}_{2}$ emissions occur at the power plant) whilst borough contributions to the flux footprint $\left(\phi_{i}\right)$ were calculated on a half-hourly basis by the KM Excel tool. For the purpose of comparing eddy-covariance measurements with NAEI data, only half-hourly averaging intervals for which at least $99 \%$ of the flux footprint lay within the boroughs were considered here. Diurnal trends were super-imposed onto $\mathrm{CO}_{2}$ emissions from natural gas usage and traffic, whilst other sources of $\mathrm{CO}_{2}$ considered by the NAEI were assumed to have constant emission rates. Further details about the methodology are provided in Sect. 2.2 of the Supplement.

\subsection{Estimation of $\mathrm{CO}_{2}$ uptake by photosynthetic activity}

Net ecosystem exchange (NEE) was estimated from tree productivity and grassland light-response data with a view to evaluate the fluxes obtained by eddy-covariance. According to a report released by the Mayor of London in March 2005 (Mayor of London, 2005), 95\% of trees in central London are broadleaved species ranging from 25 to 300 years in age. Within the tower footprint, average tree densities are of the order of 30 to 40 trees ha $^{-1}$, with most trees considered to be isolated rather than part of stands. For the estimation of the magnitude of atmospheric $\mathrm{CO}_{2}$ uptake by trees (all boroughs), net assimilation was assumed to be independent of age and species; as an approximation, a benchmark value of $6 \mathrm{~kg} \mathrm{C}$ tree $^{-1} \mathrm{y}^{-1}$ (growing season), reported for a dominant beech specimen, was used (Lebaube et al., 2000). Net assimilation due to grassy areas (borough of Westminster only as grass coverage for the entire footprint area was approximated to the surface areas of Hyde Park and the Regent's Park, both located in Westminster) was estimated from light and temperature response curves parameterised on the productivity of a managed grassland, dominated by Lolium perenne (ryegrass), near Edinburgh (UK, 55 $51.323^{\prime} \mathrm{N}, 3^{\circ} 11.705^{\prime} \mathrm{W}$; data obtained from the Centre for Ecology and Hydrology, Edinburgh station).

\section{Results and discussion}

\subsection{Local atmospheric stability and footprint analysis}

For the year (1 January 2007 to 31 December 2007), 54\% of half-hourly averages of all observed and calculated quantities were available. This period was divided into four seasons (Table 1). Data coverage was high in winter and summer (76\% and $84 \%$ respectively) whilst less than $50 \%$ of seasonal data was available in spring and autumn ( $45 \%$ and $44 \%$ of data available, respectively). Instrument downtime was the main cause of missing data throughout the 2007 study and since it occurred randomly, there is no reason to believe that diurnal trends discussed in this paper were biased towards daytime or night time regimes. The impact on seasonal trends is however more difficult to quantify, especially since it was the transitional seasons (here we mean transitions between regimes of vegetative dormancy and high natural gas demand towards heightened vegetative activity and reduced needs for domestic and commercial heating) that were the most affected. It was therefore assumed that the available data was representative of the whole season in each case.

Dominant south-westerly winds accounted for $46 \%$ of the annual wind occurrence and over $60 \%$ in both winter and summer time periods. The North-West quadrant had the second largest frequency in spring and autumn. The footprint is sensitive to atmospheric stability. As expected, unstable periods were longer and more frequent in spring and summer due to thermal mixing (Fig. 1). Unstable conditions occurred frequently during night-time and in winter when the average sensible heat flux was positive. Stable conditions were most common in autumn, presumably when the available energy (from net radiation and anthropogenic heat output) was at its minimum. On individual days in autumn and winter the sensible heat fluxes remained negative. However simultaneous sensible heat flux measurements at a rooftop site at the Westminster Council building, $2.1 \mathrm{~km}$ west of the BT tower, 
Table 1. Median seasonal daytime (09:00-18:00) stability and fetch parameters $x_{\max }$ (distance from the measurement point contributing the most to the observed flux) and $x_{90}$ (distance from the measurement point where $90 \%$ of the cumulative flux is realised). $x_{\max }$ and $x_{90}$ were obtained from the Kormann-Meixner model for each $30 \mathrm{~min}$ stability value. Seasonal data coverage is given both in relative (percentage of available data points) and absolute terms (number of available half-hourly data points).

\begin{tabular}{llllrr}
\hline & Definition & $\begin{array}{l}\text { Data } \\
\text { coverage }\end{array}$ & $\begin{array}{l}\text { Daytime } \\
\text { stability }\end{array}$ & $x_{\max }[\mathrm{km}]$ & $x_{90}[\mathrm{~km}]$ \\
\hline Winter & Dec-Feb & $63 \%(2722)$ & -0.2 & 1.7 & 13.9 \\
Spring & Mar-May & $42 \%(1855)$ & -0.4 & 1.3 & 10 \\
Summer & Jun-Aug & $72 \%(3180)$ & -0.8 & 1 & 6.9 \\
Autumn & Sep-Nov & $41 \%(1791)$ & -0.2 & 1.7 & 13.9 \\
\hline
\end{tabular}

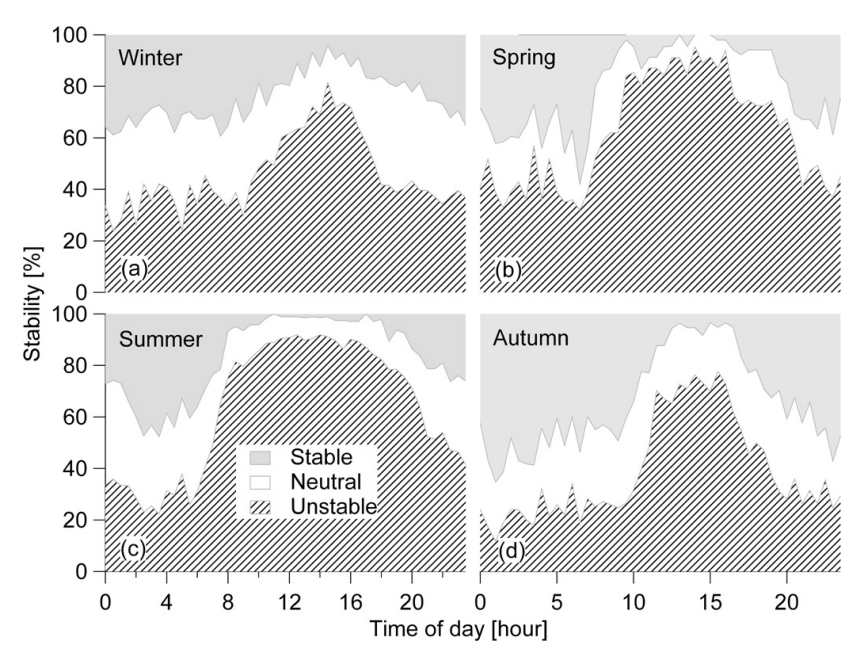

Fig. 1. Frequency distributions of unstable $(\zeta<-0.05)$, nearneutral $(-0.05 \leq \zeta \leq 0.32)$ and stable $(\zeta>0.32)$ stability conditions at the measurement height by time of day and season (a) winter (b) spring (c) summer (d) autumn (see Table 1 for definitions).

observed $\zeta>0.1$ for only $3 \%$ of the half-hour periods and the sensible heat fluxes were found to be almost always positive (Wood et al., 2010b).

The footprint of the two sites is obviously different and the BT tower measurement will be more affected by the urban parks, but the observation of stable stratification at the tower height also points to the presence of an inversion layer, during which the tower height is above the layer connected to the urban surface below, consistent with investigation of the vertical boundary layer structure during the REPARTEEII campaign (Barlow et al., 2010). In these conditions, the use of the measured stability may still underestimate the footprint. Using the local stability on the BT tower, the KM footprint model predicts that the distance from the BT tower contributing the maximum to the measured trace gas flux $\left(x_{\max }\right)$ peaked at $1600 \mathrm{~m}$ and $3000 \mathrm{~m}$ under unstable and stable atmospheric stratification, respectively (Fig. 2). Under unstable atmospheric stratification $(-6<\zeta<-0.05)$, sources contributing to $\mathrm{CO}_{2}$ fluxes measured atop the BT tower were contained within ca. 2 to $22 \mathrm{~km}$ radius circles

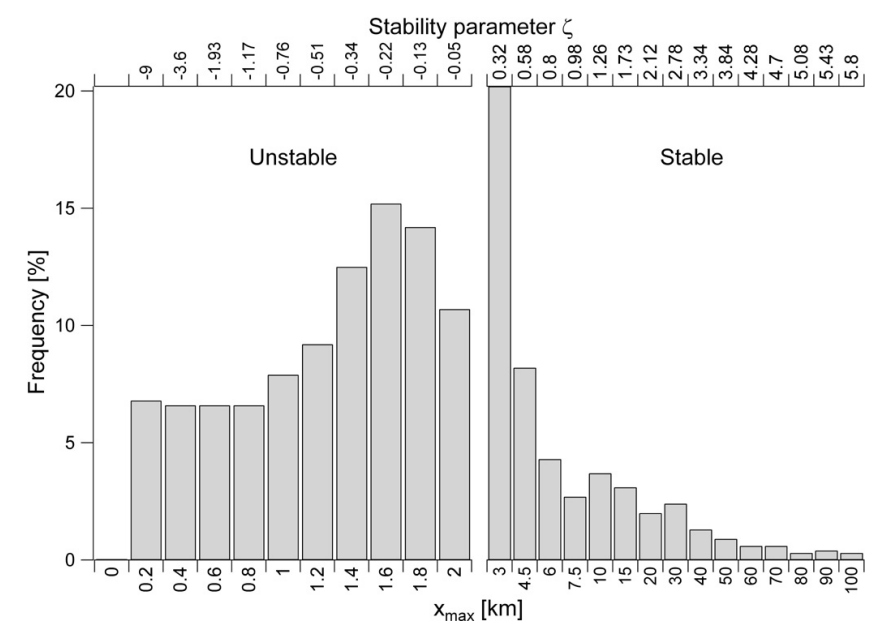

Fig. 2. Frequency distribution of the KM footprint calculated maximum contribution $\left(x_{\max }\right)$ to the measured $\mathrm{CO}_{2}$ flux - in 2007, as a function of atmospheric stability for $30 \mathrm{~min}$ periods $\left(x_{\max }\right.$ and $\zeta$ values denote the beginning of each interval).

(based on $90 \%$ of the total flux), centred on the BT tower; the corresponding range is ca. 40 to $182 \mathrm{~km}$ under stable stratification $(0.05>\zeta>6)$ and ca. $32 \mathrm{~km}$ for near-neutral conditions. The boroughs contributing the most to the flux measured at the BT tower were located in the south-west quadrant (Fig. 3). The central borough of Westminster, which stretches ca. 3-4 km from the tower mainly in the south-west quadrant, contributed $65.1 \%$ averaged over the whole year with a maximum of $82.8 \%$ reached in summer (daytime values - 09:00-18:00). This is consistent with increased occurrences of unstable atmospheric conditions during the warmer summer months and the associated contraction of the flux footprint. For the quantitative comparison between measured fluxes with NAEI predictions, the footprint model was applied to daytime periods (09:00-18:00) dominated by unstable stratification for which it was implicitly assumed that the tower was connected to the surface. This is consistent with the study of Wood et al. (2010a) which shows that the tower is indeed coupled to the surface under both neutral and unstable stratification. 


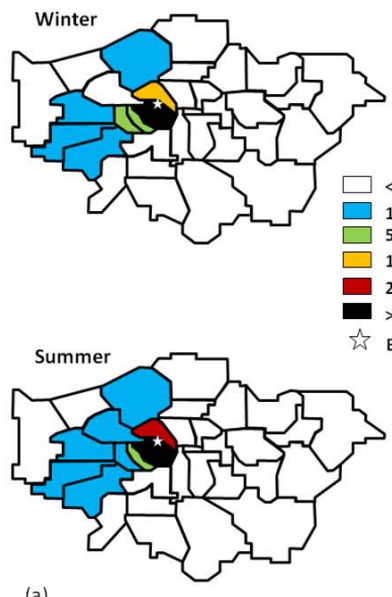

(a)

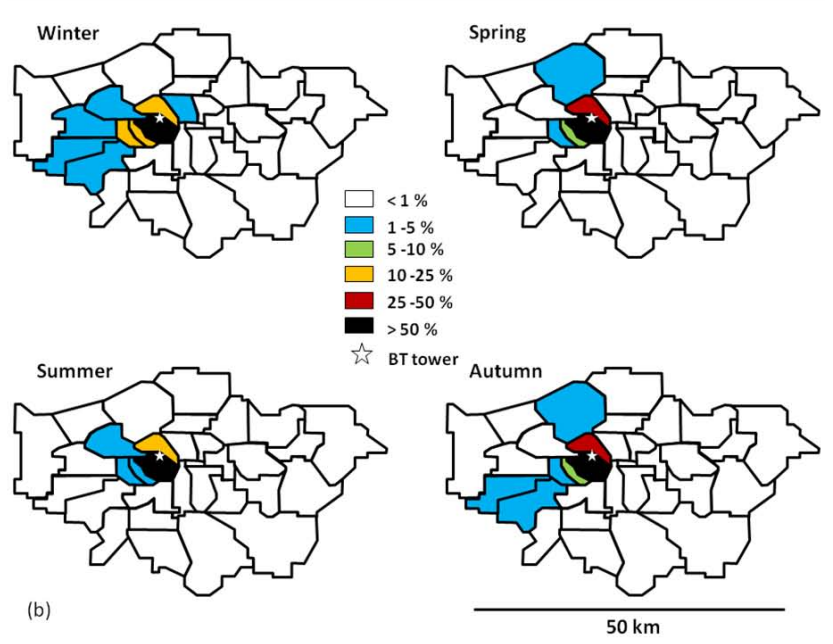

Fig. 3. Seasonal distributions during 2007 of the flux footprint of the BT Tower over Greater London. The tower footprint was calculated on a half-hourly basis using the Kormann-Meixner model. Seasonal averages were derived from (a) all available data, and (b) daytime (09:00-18:00) data only. The colour scale reflects the contribution of individual boroughs to the total flux footprint. Maps generated from $1 \mathrm{~km}^{2}$ grid data (as used by the NAEI).

\subsection{Surface and turbulence characteristics}

Building heights, and consequently roughness length, exhibit a heterogeneous distribution in the circular central area stretching approximately $5 \mathrm{~km}$ from the tower (Evans, 2009). Beyond this circle, building heights become more homogeneous towards residential areas. Stability and hence flux footprint exhibited seasonal variations in 2007 (Table 1); turbulence characteristics based on relationships between normalised wind and $\left[\mathrm{CO}_{2}\right]$ standard deviations and stability parameter $(\zeta)$ - Eqs. (2) and (3) - were evaluated. They presented some seasonal variability (Fig. 4a and b) which was not deemed to be statistically significant due to the relatively large spread across all datasets.

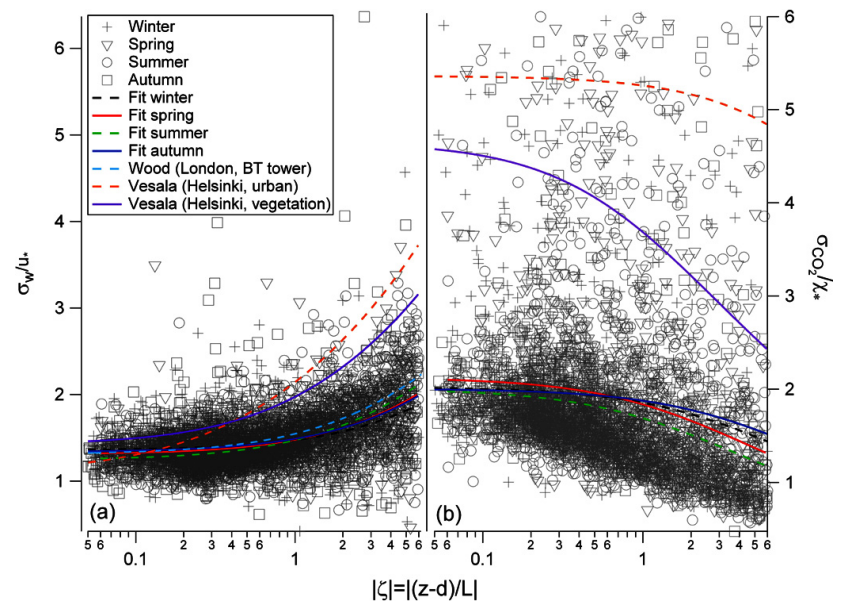

Fig. 4. Normalised standard deviation of (a) $w$ and (b) $\left[\mathrm{CO}_{2}\right]$, as a function of seasonal stability $(\zeta<0$, unstable; NB: the absolute value of $\zeta$ is used in the graph). The fit obtained by Wood (Wood et al., 2010a) using 2007/2008 tower data (Fig. 4a only) and regression results for two land-use classes (urban and vegetation) in Helsinki (Vesala et al., 2008) are also plotted.

Coefficients of $\sigma_{w} / u_{*}$ for 2007 were comparable with those derived by Wood et al. (2010a) for the 2007/08 data measured at the tower and $C_{1}$ values were also in agreement with a Helsinki site (Vesala et al., 2008). Values for parameter $C_{1}$ have been reported to decrease with increasing surface roughness (Roth and Oke, 1995; Vesala et al., 2008). In 2007, the $C_{1}$ coefficient was largest in winter, followed by autumn, spring and summer; this is consistent with seasonal changes in mean atmospheric stability (Table 1) as larger flux footprints in autumn and winter probably entrain residential and peripheral areas with more homogeneous roughness values than in central London. Values of $C_{2}$ in London were found to be significantly lower than in Helsinki for both $\sigma_{w} / u_{*}$ and $\sigma_{\mathrm{CO}_{2}} / \chi_{*}$ (Table 3). Furthermore, the best-fit lines for both $\sigma_{w} / u_{*}$ and $\sigma_{\mathrm{CO}_{2}} / \chi_{*}$ lie below the parameterisations for the urban and vegetation land-use types at the Helsinki site and exhibit a weaker dependence on stability. Wood et al. (2010a) also noted that the parameterisations of the normalised standard deviations of the wind velocity components resembled more those found in the rural surface layer than above cities, which could be an effect of the high measurement height.

\subsection{Concentrations}

The range of $\mathrm{CO}_{2}$ concentrations observed is comparable with data in the literature for other urban areas, although no other measurements have been taken at similarly large a $z_{\mathrm{m}} / z_{\mathrm{H}}$ ratio $\left(z_{\mathrm{m}} / z_{\mathrm{H}} \approx 22\right.$, compared to buildings within 1$10 \mathrm{~km}$ from the BT tower site; Wood et al., 2010a). Carbon dioxide concentrations measured at the BT tower were in the range $370 \mathrm{ppm}$ to $397 \mathrm{ppm}$ for the period October 2006 to December 2007, with peak values in February and minimum 


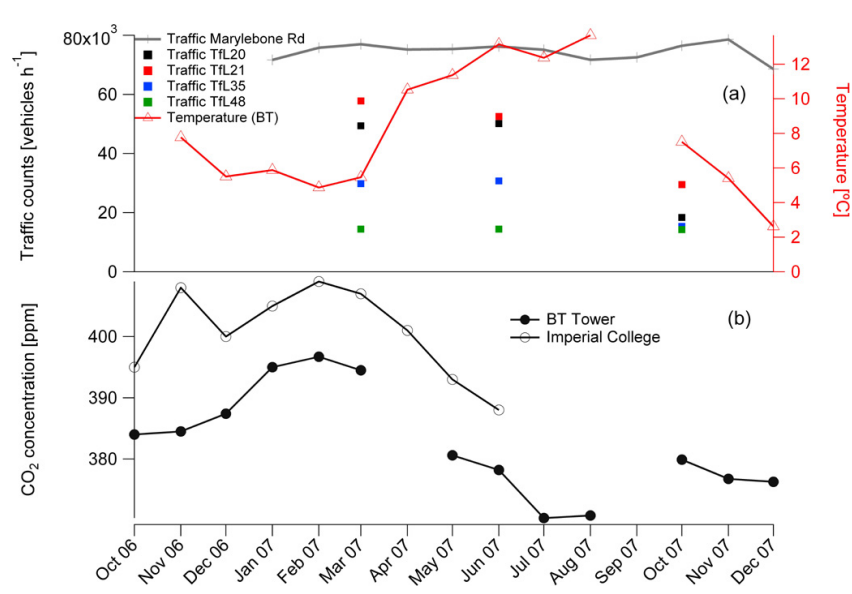

Fig. 5. (a) Traffic counts at Marylebone Road and four Transport for London (TfL) census sites, and temperature measured at the BT Tower in 2007; (b) comparison of mean monthly $\mathrm{CO}_{2}$ concentrations measured at the BT Tower and a tower site at Imperial College London (at $87 \mathrm{~m}$ ) (Fig. S1, Supplement) (Rigby et al., 2008). BT Tower data for April and September 2007 were excluded since the temporal data coverage was less than $10 \%$.

values in July and August (Fig. 5), based on 30-min averages. This is consistent with the effect of the annual photosynthetic uptake of vegetation, which provides a net sink for $\mathrm{CO}_{2}$ in summer and a net source in winter (Hall et al., 1975; Keeling et al., 1996; Buermann et al., 2007).

The BT tower data were compared to a second tall tower site $(87 \mathrm{~m})$ at the Imperial College of London (Rigby et al., 2008), located ca. $3.5 \mathrm{~km}$ south-west of the BT tower along the dominant wind direction (Fig. S1, Supplement). The $\mathrm{CO}_{2}$ concentrations exhibited a similar trend, with a nearconstant offset of $11.5 \mathrm{ppm}$, except for a peak in November 2006, which was observed solely at the Imperial College tower. For this month the difference in the mean monthly values is $23.5 \mathrm{ppm}$. Although a common calibration was not conducted, the increased concentration at the lower level is consistent with the expected concentration gradient above a city. Furthermore, the Imperial College tower measurements could have been more influenced by nearby micro/local-scale sources. Since vertical mixing is likely to be more efficient during summer, the gradient would be expected to show an annual cycle, being largest in winter. However, this was not reflected in the measurements. Possibly, the measurement at the Imperial College site was already made above the stable boundary layer during winter inversion conditions.

The common peak concentration in February 2007 coincided with the coldest month of the 2006/2007 winter, which is consistent with inverse correlation to mean air temperatures. This suggests that commercial, industrial and residential fossil fuel consumption for heating purposes contribute to the seasonal trend of $\mathrm{CO}_{2}$ emissions. The magnitude of this contribution could not be separated from the natural photosynthetic/respiration cycle.
Table 2. Average daily traffic counts at Marylebone road and four Transport for London (TfL, with permission) sites in March, June and October 2007.

\begin{tabular}{llll}
\hline Unit: number of vehicles & March & June & October \\
\hline Marylebone Road & 76955 & 76201 & 76465 \\
TfL 20 (Camden) & 49384 & 50141 & 18357 \\
TfL 21 (Kensington \& Chelsea) & 57815 & 52564 & 29497 \\
TfL 35 (Westminster) & 29809 & 30721 & 15367 \\
TfL 48 (Camden) & 14438 & 14422 & 14248 \\
\hline
\end{tabular}

\subsubsection{Seasonal variability}

Road traffic, whose emissions were estimated to account for $33 \%$ of the annual $\mathrm{CO}_{2}$ emissions from the borough of Westminster in 2006 and $42 \%$ from all boroughs (NAEI, 2009), was fairly constant from February to July 2007 (Fig. 5). Traffic volume measured on Marylebone Road decreased by ca. 6\% in December 2006, August-September 2007 and December 2007, compared with all other months, but this was not unequivocally linked to changes in $\mathrm{CO}_{2}$ concentrations measured at the BT tower. Marked drops in traffic loads (Table 2) were recorded between June and October at three out of four Transport for London (TfL) monitoring sites (Fig. S1, Supplement). Whilst these sites were located in the boroughs contributing the most to the flux footprint measured at the tower (Westminster, Camden and Kensington \& Chelsea), $\left[\mathrm{CO}_{2}\right]$ did not reflect these changes in traffic loads. This could suggest that traffic was not the foremost mechanism affecting seasonal variations in concentrations. Rigby et al. (2008), who studied $\mathrm{CO}_{2}$ mixing ratios atop a tall tower at the Imperial College in London (UK) between August 2006 and June 2007 (Fig. 5b), report low concentrations in summer - limited by traffic and biospheric uptake whilst increased values in winter time are attributed to added emissions from natural gas burning. Furthermore, summer time concentrations are lower than winter time ones across the entire dominant stability range (Fig. 6a), which suggests that dilution by entrainment does not control seasonal trends to a great extent.

The extent of the apparent spatial heterogeneity of traffic loads could not be probed any further due to lack of detailed spatial data. However, Marylebone road provides excellent temporal resolution (continuous hourly data) for 2007. The spatial data may be impacted by local activities (e.g. localised traffic disruptions to the traffic census sites Tfl 20,21 and 35 in October 2007), or the extension of the Congestion Charge Zone (CCZ), implemented in February 2007, but the magnitude of these impacts are unknown. However, diurnal trends at the four $\mathrm{TfL}$ sites used in this study were strongly correlated with traffic counts observed at Marylebone Road ( $R^{2} \sim 0.8-0.9$; data not shown) which supports the use of the latter site as a proxy representative of central London. 

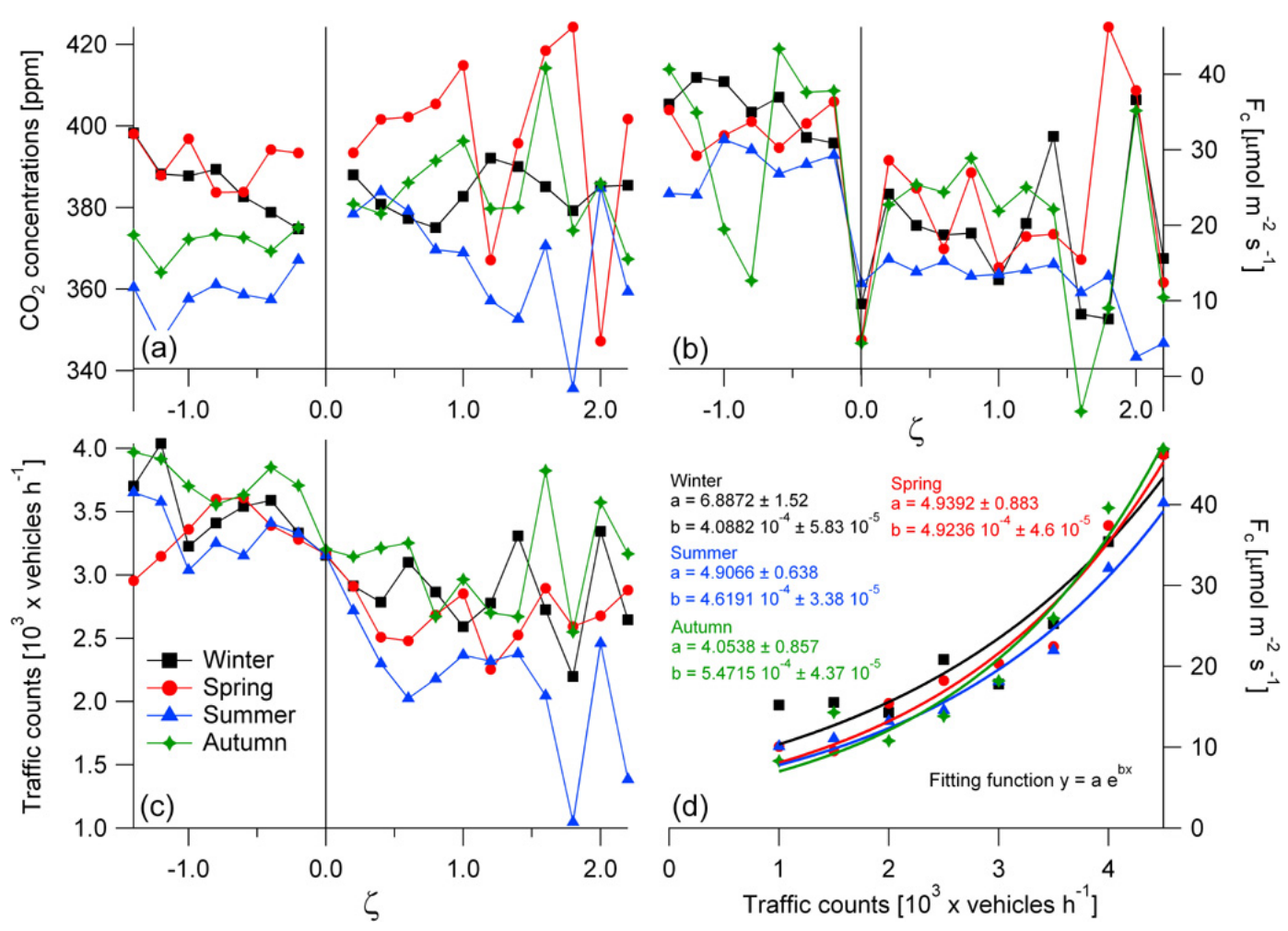

Fig. 6. (a) $\mathrm{CO}_{2}$ concentrations, (b) $\mathrm{CO}_{2}$ fluxes, (c) traffic counts as a function of atmospheric stability and (d) $\mathrm{CO}_{2}$ fluxes as a function of traffic counts.

Table 3. Coefficients for normalised standard deviation of vertical wind velocity and $\mathrm{CO}_{2}$ concentration (Eqs. 2 and 3 ) by seasons (2007, this study), 2007/2008 (Wood et al., 2010a) and for two landuse classes (urban and vegetation) observed in a study in Helsinki, Finland (Vesala et al., 2008).

\begin{tabular}{llllr}
\hline & $\sigma$ & $C_{1}$ & $C_{2}$ & $C_{3}$ \\
\hline Winter 2007 & $w$ & 1.36 & 0.28 & $1 / 3$ \\
& $\mathrm{CO}_{2}$ & 2.02 & 0.30 & $-1 / 3$ \\
\hline Spring 2007 & $w$ & 1.31 & 0.44 & $1 / 3$ \\
& $\mathrm{CO}_{2}$ & 2.12 & 0.54 & $-1 / 3$ \\
\hline Summer 2007 & $w$ & 1.24 & 0.66 & $1 / 3$ \\
& $\mathrm{CO}_{2}$ & 2.00 & 0.66 & $-1 / 3$ \\
\hline Autumn 2007 & $w$ & 1.33 & 0.38 & $1 / 3$ \\
& $\mathrm{CO}_{2}$ & 2.00 & 0.22 & $-1 / 3$ \\
\hline London & $w$ & 1.31 & 0.65 & $1 / 3$ \\
(2007/2008) & & & & \\
\hline Urban & $w$ & 1.11 & 6.18 & $1 / 3$ \\
(Helsinki) & $\mathrm{CO}_{2}$ & 5.36 & 0.06 & $-1 / 3$ \\
\hline Vegetation & $w$ & 1.42 & 1.68 & $1 / 3$ \\
(Helsinki) & $\mathrm{CO}_{2}$ & 4.65 & 1.01 & $-1 / 3$ \\
\hline
\end{tabular}

Atmos. Chem. Phys., 11, 1913-1928, 2011
Based on traffic figures and the relation between $\mathrm{CO}_{2}$ concentrations and atmospheric stability it seems likely that temperature-dependent fluctuations in demand for natural gas combined with seasonal changes in biospheric uptake control the seasonal trends in atmospheric $\mathrm{CO}_{2}$ concentrations.

\subsubsection{Diurnal dynamics}

Diurnal courses of urban $\mathrm{CO}_{2}$ concentrations $\left(\left[\mathrm{CO}_{2}\right]\right)$ are affected by temporal changes in boundary layer height, anthropogenic emissions, biosphere exchange and vertical mixing. The measurements have distinct hourly and diurnal spatial patterns as illustrated in Fig. 7a-b in which concentrations are plotted as a function of wind direction, time of day (a) and day of the week (b). Increased concentrations were observed in the north-east and south-east quadrants in the latter part of the evening (20:00-00:00) (Fig. 7a), as well as during the night (00:00-08:00) in the north-east and northwest quadrants. These concentration build-ups are consistent with a reduction in mixing due to night-time boundary layer shrinkage. The nocturnal build-up in the north-west quadrant was accompanied by a marked daytime reduction in concentrations $(\sim 10: 00-16: 00)$. Because this wind sector has a large fractional vegetation cover, especially in the 


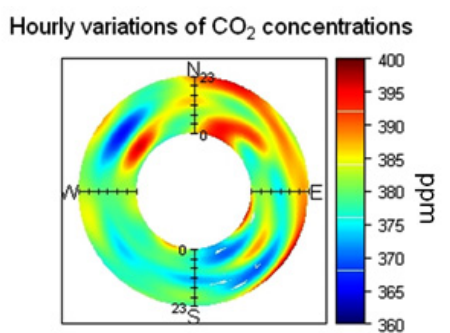

(a)

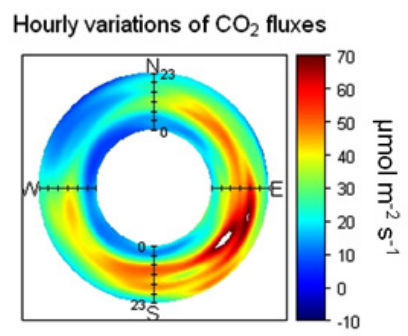

(d)

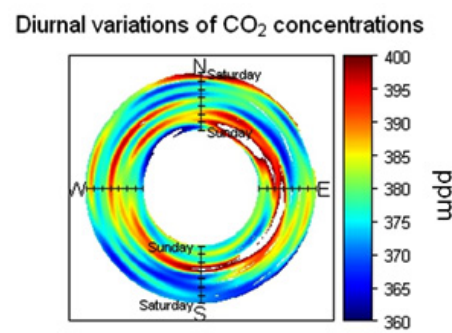

(b)

Diurnal variations of $\mathrm{CO}_{2}$ fluxes

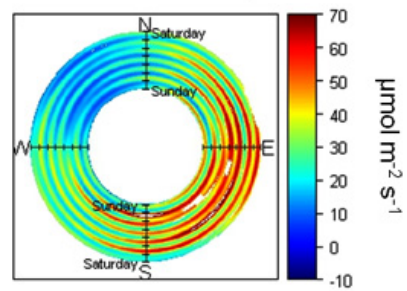

(e)

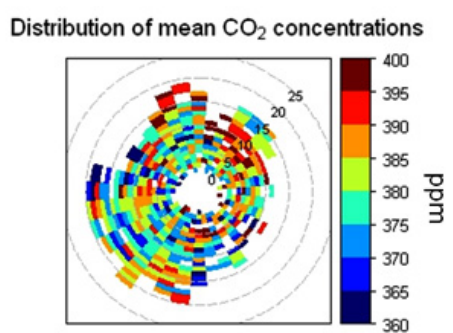

(c)

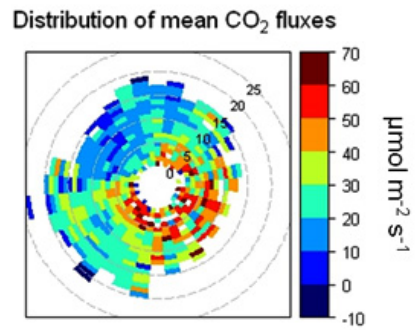

(f)

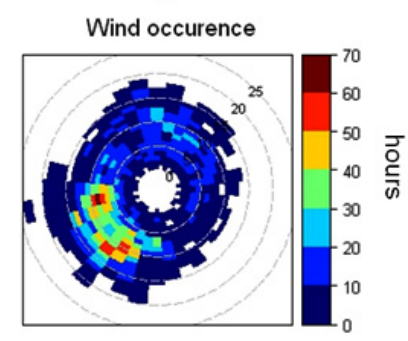

(g)

Fig. 7. $\mathrm{CO}_{2}$ concentrations (in ppm) as a function of wind direction average (a) hourly and (b) diurnal variations; variations of $\mathrm{CO}_{2}$ fluxes (in $\mu \mathrm{mol} \mathrm{m} \mathrm{m}^{-2} \mathrm{~s}^{-1}$ ) as a function of wind direction average (d) hourly and (e) diurnal; (c), (f) distribution of $\mathrm{CO}_{2}$ concentrations (ppm) and $\mathrm{CO}_{2}$ fluxes ( $\mu \mathrm{mol} \mathrm{m} \mathrm{m}^{-2} \mathrm{~s}^{-1}$ ) as a function of wind direction and wind speed; (g) wind occurrence (in hours) as a function of wind speed and direction. Plots were generated using the openair (Carslaw and Ropkins, 2010) package for R (R Development Core Team, 2009).

daytime footprint due to The Regent's Park, the diurnal pattern for north-westerly wind was very likely more affected by diurnal plant assimilation/ respiration cycles.

Overall, daytime concentrations were less than at nighttime, consistent with fluctuations in boundary layer height. Analysis of mean concentrations as a bi-variate function of wind speed and direction (Fig. 7c) shows that the largest concentrations were observed from the north and north-east of the tower especially at high wind speed $\left(\geq \sim 10 \mathrm{~m} \mathrm{~s}^{-1}\right)$. Rises in $\mathrm{CO}_{2}$ concentrations in the north-east quadrant were not accompanied by surges in $\mathrm{CO}_{2}$ fluxes, which were largest in the south-east quadrant where they ranged from $\sim 20$ $60 \mu \mathrm{mol} \mathrm{m}{ }^{-2} \mathrm{~s}^{-1}$, (Fig. 7d-f) whilst fluxes in the three other quadrants were in the $0-40 \mu \mathrm{mol} \mathrm{m}^{-2} \mathrm{~s}^{-1}$ range. The level of $\mathrm{CO}_{2}$ concentrations observed in the north-east quadrant could have been caused by horizontal transport (north-east winds in the UK are often associated with cyclonic transport of polluted European continental air masses) and reduced vertical mixing. Averages for north and north-east conditions may further have been affected by the relative small number of observations under these conditions (Fig. 7g). This is also true for the south-east quadrant which had the lowest wind occurrence but the highest $\mathrm{CO}_{2}$ fluxes.

In winter and autumn a gradual decrease in concentrations occurred from ca. 10:00 until a minimum at mid-afternoon (ca. 14:00-15:00) (not shown). Concentrations increased from this point until ca. 17:00-18:00 after which they remain relatively constant throughout the night. These diurnal patterns are consistent with those observed in Edinburgh (Nemitz et al., 2002), Tokyo (Moriwaki and Kanda, 2004) and Basel (Vogt et al., 2006). In contrast, spring and summer concentrations have local minima at around 12:00 noon and 16:00, and local maxima around 14:00. Summer time concentrations were generally lower than any other season, whilst spring time values were the highest, especially at night time.

On a diurnal basis, $\mathrm{CO}_{2}$ concentrations appear not to be correlated with traffic density with the minimum $\left[\mathrm{CO}_{2}\right]$ associated with afternoon peak traffic counts and whilst $\left[\mathrm{CO}_{2}\right]$ increased during the night when traffic counts were at their minimum. This is consistent with the observations made by Rigby et al. (2008) and can be explained by the overriding 
effect of the growth of the mixed layer and entrainment of air less concentrated in $\mathrm{CO}_{2}$ from above during the day (Reid and Steyn, 1997). As shown in Fig. 6a, there is a correlation between atmospheric stability (at the measurement height) and $\mathrm{CO}_{2}$ concentrations in the near-neutral range, especially for values of the local stability parameter $(\zeta=z / L)$ in the range -1.5 to +2 , where over $90 \%$ of available data points were found. Strong positive linear dependencies were found in spring and autumn in the narrower stability range -0.5 to +1 ( $84 \%$ of the total annual data falls into this stability range); this is also true in summer for the stability range -0.5 to +0.5 ( $82 \%$ of the total annual data). In all three cases, $\left[\mathrm{CO}_{2}\right]$ exhibited an inverse correlation to traffic counts which supports the idea that entrainment/dilution is the dominant mechanism. No such trends were however observed during the winter period, perhaps due to increased emissions from natural gas burning, although this could not be verified. Due to the corrrelation between stability and source activity, it is impossible to quantify the importance of both effects on governing concentrations more fully. In addition, during night-time (when most of the stable conditions occur) emissions are dominated by gas combustion rather than traffic. However, overall it appears that fluctuations in $\mathrm{CO}_{2}$ concentrations on the BT tower were driven also by dilution rather than by changes in local sources strength alone.

\subsection{Fluxes}

\subsubsection{Flux losses due to high-pass filtering}

Comparison of 30-min fluxes with calculations based on 2-h averaging showed that losses due to high-pass filtering were $<5 \%$ irrrespective of time of day and season (Fig. S4, Supplement).

In contrast, for 25-min averaging times, Langford et al. (2010) derived flux losses of 5.8\% and $8 \%$ for $\mathrm{H}_{3-30}$ ( $1.5 \mathrm{~h}$ block-averaged sensible heat fluxes compared to averaging over 25-min averages within three consecutive halfhourly periods) and $H_{4-30}$, respectively, for measurements taken during October 2006 at the BT tower site (day and night regimes were not segregated from one another). Those results suggested a moderate flux loss using the shorter averaging periods due to failure to capture low-frequency components (see also Martin et al., 2009a).

Given that the flux loss of 30-min periods was $<5 \%$ and that shorter averaging times (a) are less likely to be affected by non-stationarities and (b) provide more information on variability and processes, an averaging time of $30 \mathrm{~min}$ was selected.

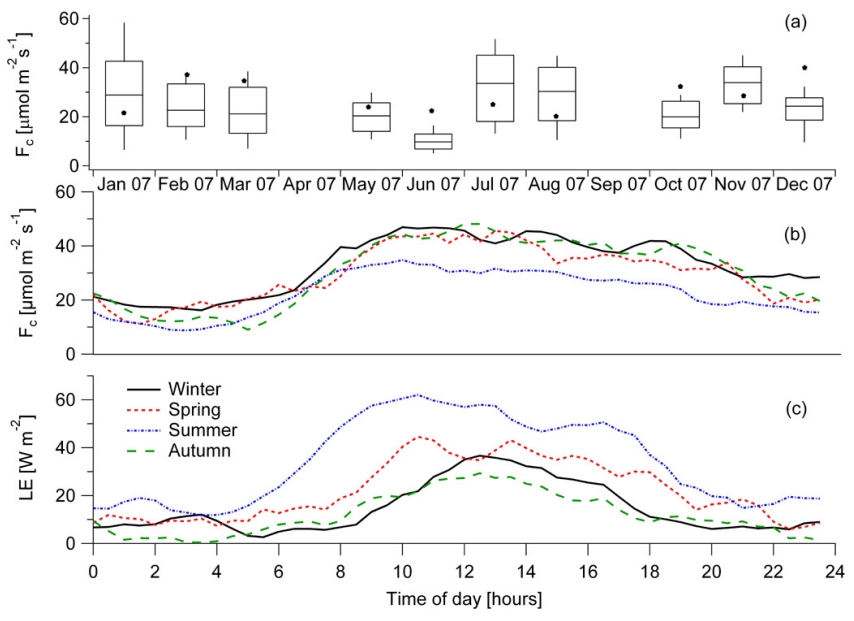

Fig. 8. (a) Monthly breakdown of $\mathrm{CO}_{2}$ flux statistics for 2007 (bottom and top of boxes correspond to 25 th and 75 th percentiles, respectively; bottom and top whiskers correspond to 10th and 90th percentiles, respectively; monthly means and medians are indicated by solid markers and horizontal lines, respectively), and seasonal trends in (b) $\mathrm{CO}_{2}$ and (c) latent heat fluxes. Winter is defined as December 2006-February 2007, spring is March-May 2007, summer is June-August 2007 and autumn is September-November 2007.

\subsubsection{Traffic and seasonal controls}

\section{Traffic}

Unlike $\mathrm{CO}_{2}$ concentrations, the fluxes of $\mathrm{CO}_{2}\left(F_{\mathrm{c}}\right)$ are correlated with Marylebone Road traffic counts throughout the year (Fig. 6d). The data in Fig. 6d are the observed fluxes so include the net exchange from all the sources and sinks, and the diurnal variability. On average, $F_{\mathrm{c}}$ ranged between ca. 7 and $47 \mu \mathrm{mol} \mathrm{m}^{-2} \mathrm{~s}^{-1}$ (consistent with other urban sites reported in the literature, Table 4) although excursions towards much larger values (maximum $167 \mu \mathrm{mol} \mathrm{m}^{-2} \mathrm{~s}^{-1}$ ) were sometimes observed (Fig. 8a). From fitting a first order exponential function, background emissions (i.e. intercepts for zero traffic counts) were estimated. They ranged from 4 to $7 \mu \mathrm{mol} \mathrm{m}^{-2} \mathrm{~s}^{-1}$ and correspond to an emission of $33400 \mathrm{t} \mathrm{CO}_{2} \mathrm{~km}^{-2} \mathrm{y}^{-1}$ from non-traffic-based activities. This is $11 \%$ higher than the 2006 NAEI value of $29919 \mathrm{tCO}_{2} \mathrm{~km}^{-2}, \mathrm{y}^{-1}$ for non-traffic emissions, but unlike the NAEI also includes the biospheric signal, which at nighttime (when traffic volume is lowest) reflects emission from net respiration. The intercept was largest during winter consistent with the largest night-time heating emissions during this period.

Possible reasons for the non-linearity in the traffic dependence of the flux include: (a) other activities, such as demand for natural gas, scale non-linearly with traffic, (b) fuel consumption increases at high traffic volumes, (c) the Marylebone Road traffic counts underestimate the full dynamic range of the average traffic activity in the flux footprint 
due to saturation at high traffic volumes, and (d) changing meteorology (e.g. boundary layer height) with season at rush hours.

The latter is illustrated in Fig. 6c which shows that high traffic counts were generally recorded at times dominated by unstable stratification. $\mathrm{CO}_{2}$ fluxes $\left(F_{\mathrm{c}}\right)$ are inversely correlated to stability (i.e. unstable stratification is often accompanied by higher flux values), as shown in Fig. $6 \mathrm{~b}$ and positively correlated to traffic counts (Fig. 6d). The relationship between traffic counts and stability (this is obviously not causal) is of a sigmoidal nature over the stability range -1.5 to +2 , where over $90 \%$ of available data points were found. In light of this, it is difficult to quantify unequivocally how much of the variability in the $\mathrm{CO}_{2}$ flux measured well above the city is associated with the variability in traffic volume and how much reflects changes in atmospheric factors.

Similarly, the interpretation of the difference between weekday and weekend, in averaged diurnal cycles in Marylebone Road traffic volume and measured $\mathrm{CO}_{2}$ flux (Fig. 9), is not straightforward. Although, at the annual average level (not shown), traffic counts measured on Marylebone Rd were virtually identical at midday (difference of $1.7 \%$ ), measured fluxes were $\sim 29.2 \pm 6.7 \mu \mathrm{mol} \mathrm{m}^{-2} \mathrm{~s}^{-1}$ at weekends compared with $38.0 \pm 8.0 \mu \mathrm{mol} \mathrm{m} \mathrm{m}^{-2} \mathrm{~s}^{-1}$ on weekdays (23\% discrepancy). This would imply that non-traffic sources make a larger relative contribution on weekdays than at weekends, which is also reflected in an increased ratio between $\mathrm{CO}_{2}$ flux and traffic flow during all seasons (Fig. 9).

Based on traffic data, the weekday/weekend comparison also suggests that the tower may have been decoupled from street level at night time when stable or neutral stratification were dominant throughout the year. Measured fluxes were very similar despite a considerable difference in the traffic patterns: during all seasons traffic was $\sim 35 \%$ heavier between midnight and 04:00 at the weekends and reached a minimum at around 05:00 (possibly coinciding with nightclub closing time and the resuming of public transport services). Traffic increased steadily - and almost linearly thereafter before reaching an almost constant value from $\sim$ 13:00 until 19:00. Weekday traffic volumes were on average 15\% higher between 05:00 and 13:00 and grew more rapidly from 05:00 until 08:00. However, weekday and weekend $\mathrm{CO}_{2}$ fluxes were almost identical in magnitude and trend between midnight and 08:00 and until 05:00 the ratio between $\mathrm{CO}_{2}$ fluxes and traffic numbers was larger on weekdays than at the weekend by ca. a factor of 1.5 to 2 , in all seasons except spring. This suggests that (a) at night the net $\mathrm{CO}_{2}$ flux was dominated by other (non-traffic) sources, (b) that night-time weekend Marylebone Road traffic loads are not representative of other areas within the flux footprint or (c) that decoupling from the surface occurred at night (although it was not possible to determine how frequently this might have been the case). Since there is no reason to assume that stability was (on average) different between weekdays and weekends, the lower flux/traffic ratio at weekends suggests that the night-time emission was dominated by nontraffic sources. While the nocturnal footprint was larger than during the day (and may therefore have been biased towards more residential areas) there was no significant difference in the wind frequency distribution during day and night-time.

There is on average a time-lag between the increase in traffic in the morning and the increase in the measured $\mathrm{CO}_{2}$ flux and the ratio tends to dip between 06:00 and 09:00 and peak between 09:00 and 12:00, an observation that was less visible at the weekends, probably due to the slower increase in traffic numbers during the morning. This would be consistent with early morning emissions being injected into a shallow residual layer and only contributing to the flux at the tower height as this layer expands later in the morning. Thus there is also indication that nocturnal decoupling did affect the fluxes. Gradient measurements below the flux measurement height would be required to quantify the storage in more detail.

Although average fluxes remained positive, daytime values did decrease in the summer ( 8 to $35 \mu \mathrm{mol} \mathrm{m}{ }^{-2} \mathrm{~s}^{-1}$ ); this was accompanied by an increase in latent heat fluxes (LE) (Fig. 8c). The mean decrease in $F_{\mathrm{c}}$ observed during the summer months is equivalent to $567 \mathrm{tCO}_{2} \mathrm{~km}^{-2}$ month ${ }^{-1}$ compared with winter (winter and summer data were used so as to compare periods of vegetative dormancy with the fullydeveloped growing season) which is $13 \%$ larger than the summer to winter deficit obtained from the cumulative contributions of $F_{\mathrm{c}-\text { gas }}$, human $\mathrm{CO}_{2}$ emissions and biosphere exchange in Sects. 2.5 and 2.6. In contrast, seasonal fluctuations in traffic observed at Marylebone Road and TfL sites 20,35 and 48 were negligible (e.g. $0.02 \%$ smaller in winter than in summer at Marylebone Road), whilst traffic counts were on average $10 \%$ fewer in summer than in winter at $\mathrm{TfL}$ 21 , which is located within the dominant wind sector. Furthermore, the marked drops in traffic counts observed at TfL 20, 21 and 35 (traffic counts at TfL 48 and Marylebone Road remained approximately constant) between June and October (Table 2) were not accompanied by a decrease in flux values. On the contrary, these were found to increase to levels comparable to winter and spring time. This illustrates the spatial heterogeneity of traffic volumes within the flux footprint (and the difficulty to identify a robust proxy site) and suggests that seasonal emissions trends are largely driven by the demand for natural gas and, to a lesser extent, by changes in biospheric exchange. $\mathrm{CO}_{2}$ fluxes exhibited clear diurnal trends (Fig. 7d) with maximum values observed in all quadrants between ca. 08:00 and 20:00. Unlike concentrations which peaked in the north-east quadrant, which covers a busy commercial area, the largest fluxes $\left(\sim 20-60 \mu \mathrm{mol} \mathrm{m}^{-2} \mathrm{~s}^{-1}\right)$ were found in the south-east quadrant independent of day of the week and wind speed (Fig. 7e-f). The low frequency of wind from this quadrant in 2007 (ca. 5\%; Fig. 7f) means that it made a small contribution to the total flux measured at the tower (Fig. 3) despite the seemingly strong sources located in that quadrant. 
Table 4. Recent measurements of $\mathrm{CO}_{2}$ concentrations $\left(\left[\mathrm{CO}_{2}\right]\right)$ and fluxes $\left(\mathrm{F}_{\mathrm{c}}\right)$ in different urban sites $(\mathrm{CC}-\mathrm{city}$ centre, $\mathrm{SR}-\mathrm{subur}-$ ban/residential, IN - institutional). To aid inter-annual comparison, $\left[\mathrm{CO}_{2}\right]$ were normalised by their concurrent background levels measured at the Mauna Loa observatory (Tans, 2009).

\begin{tabular}{|c|c|c|c|c|c|c|}
\hline City & Year & Season & $\begin{array}{l}\text { Site } \\
\text { type }\end{array}$ & $\begin{array}{r}\text { Height } \\
{[\mathrm{m}]}\end{array}$ & $\begin{array}{l}\text { Normalised } \\
{\left[\mathrm{CO}_{2}\right] \text { range }}\end{array}$ & $\begin{array}{r}F_{\mathrm{c}} \text { range } \\
{\left[\mu \mathrm{mol} \mathrm{m}{ }^{-2} \mathrm{~s}^{-1}\right]}\end{array}$ \\
\hline $\begin{array}{l}\text { Basel } \\
\text { Vogt et al. (2006) }\end{array}$ & 2002 & Summer & $\mathrm{CC}$ & 29 & $0.97-1.13$ & 3 to 15 \\
\hline $\begin{array}{l}\text { Chicago } \\
\text { Grimmond et al. (2000) }\end{array}$ & 1992 & Summer & SR & 27 & $1.04-1.15$ & -2 to 10 \\
\hline $\begin{array}{l}\text { Copenhagen } \\
\text { Soegaard and Moller-Jensen } \\
(2003)\end{array}$ & 2001 & Four seasons & $\mathrm{CC}$ & 40 & & 6 to 32 \\
\hline $\begin{array}{l}\text { Edinburgh } \\
\text { Nemitz et al. (2002) }\end{array}$ & 2000 & Autumn & $\mathrm{CC}$ & 65 & $0.96-1.13$ & -12 to 135 \\
\hline $\begin{array}{l}\text { Helsinki } \\
\text { Vesala et al. (2008) }\end{array}$ & 2007 & Winter-Summer & IN & 31 & & -10 to 17 \\
\hline $\begin{array}{l}\text { London - } \\
\text { this study }\end{array}$ & 2007 & Four seasons & $\mathrm{CC}$ & 190 & $0.96-1.03$ & 7 to 47 \\
\hline $\begin{array}{l}\text { London } \\
\text { Rigby et al. (2008) }\end{array}$ & 2006-2007 & Four seasons & $\mathrm{CC}$ & 87 & $1.01-1.11$ & \\
\hline $\begin{array}{l}\text { Marseille } \\
\text { Grimmond et al. (2004) }\end{array}$ & 2001 & Summer & $\mathrm{CC}$ & 44 & & 5 to 30 \\
\hline $\begin{array}{l}\text { Melbourne } \\
\text { Coutts et al. (2007) }\end{array}$ & 2004-2005 & Four seasons & SR & 40 & $0.94-1$ & 2 to 11.5 \\
\hline $\begin{array}{l}\text { Mexico City } \\
\text { Velasco et al. (2005) }\end{array}$ & 2003 & Spring & $\mathrm{CC}$ & 37 & $1.06-1.18$ & -5 to 36.4 \\
\hline $\begin{array}{l}\text { Tokyo } \\
\text { Moriwaki and Kanda (2004) }\end{array}$ & 2001-2002 & Four seasons & SR & 29 & $0.91-1.21$ & 4.5 to 25 \\
\hline
\end{tabular}

The north-west quadrant exhibited the lowest fluxes ranging between -10 and $+20 \mu \mathrm{mol} \mathrm{m}^{-2} \mathrm{~s}^{-1}$ and their diurnal cycles were in phase with those of the concentrations, which could be explained by photosynthetic activity in The Regent's Park area (1-2 km NW of the BT Tower). Wind occurrence from the north-west quadrant was however relatively low and observations extreme could have affected flux and concentration averages.

Peak fluxes $\left(\sim 50-70 \mu \mathrm{mol} \mathrm{m} \mathrm{m}^{-2} \mathrm{~s}^{-1}\right)$ in the dominant south-west wind sector occurred at relatively low wind speed $\left(<7-8 \mathrm{~m} \mathrm{~s}^{-1}\right.$; Fig. 7f) and can probably be attributed to emissions from highly-populated inner boroughs with high traffic loads such as Westminster which, according to the KM footprint, contributed $65.1 \pm 11.9 \%$ to the flux measured atop the tower over the whole year (Westminster $\sim 8000$ inhabitants $\mathrm{km}^{-2}$ (Office for National Statistics) ${ }^{5}, 433150 \mathrm{tCO}_{2}$ from traffic emissions in 2006 (NAEI)).

\footnotetext{
${ }^{5}$ http://www.statistics.gov.uk
}

\section{Comparison of bottom-up inventory (NAEI) with eddy-covariance results}

Annual average daytime (09:00-18:00) $\mathrm{CO}_{2}$ emissions rates from London boroughs measured by eddy-covariance at the telecom tower (4242 \pm 609 tons $\mathrm{CO}_{2} \mathrm{~km}^{-2}$ month $\left.^{-1}\right)$ were $3 \%$ smaller than the bottom-up flux estimated from the 2006 NAEI $\left(4377 \pm 345 \mathrm{t} \mathrm{CO}_{2} \mathrm{~km}^{-2}\right.$ month $\left.^{-1}\right)$. The NAEI derived flux omits both biosphere exchange and human exhalation, which would have contributed to the flux measurement. However, it is estimated that these two fluxes are small, similar in magnitude and approximately cancel each other out. In contrast, annual averages obtained from all available data (no restriction to the daytime period 09:00-18:00) yield emissions rates of $4194 \pm 612 \mathrm{tCO}_{2} \mathrm{~km}^{-2}$ month ${ }^{-1}$ and $4650 \pm 254 \mathrm{tCO}_{2} \mathrm{~km}^{-2}$ month $^{-1}$ for eddy-covariance and NAEI, respectively (NAEI exceeds the eddy-covariance by ca. 11\%). This might indicate an underestimation of the eddy-covariance approach over stable night time periods when the tower becomes either decoupled from the surface 


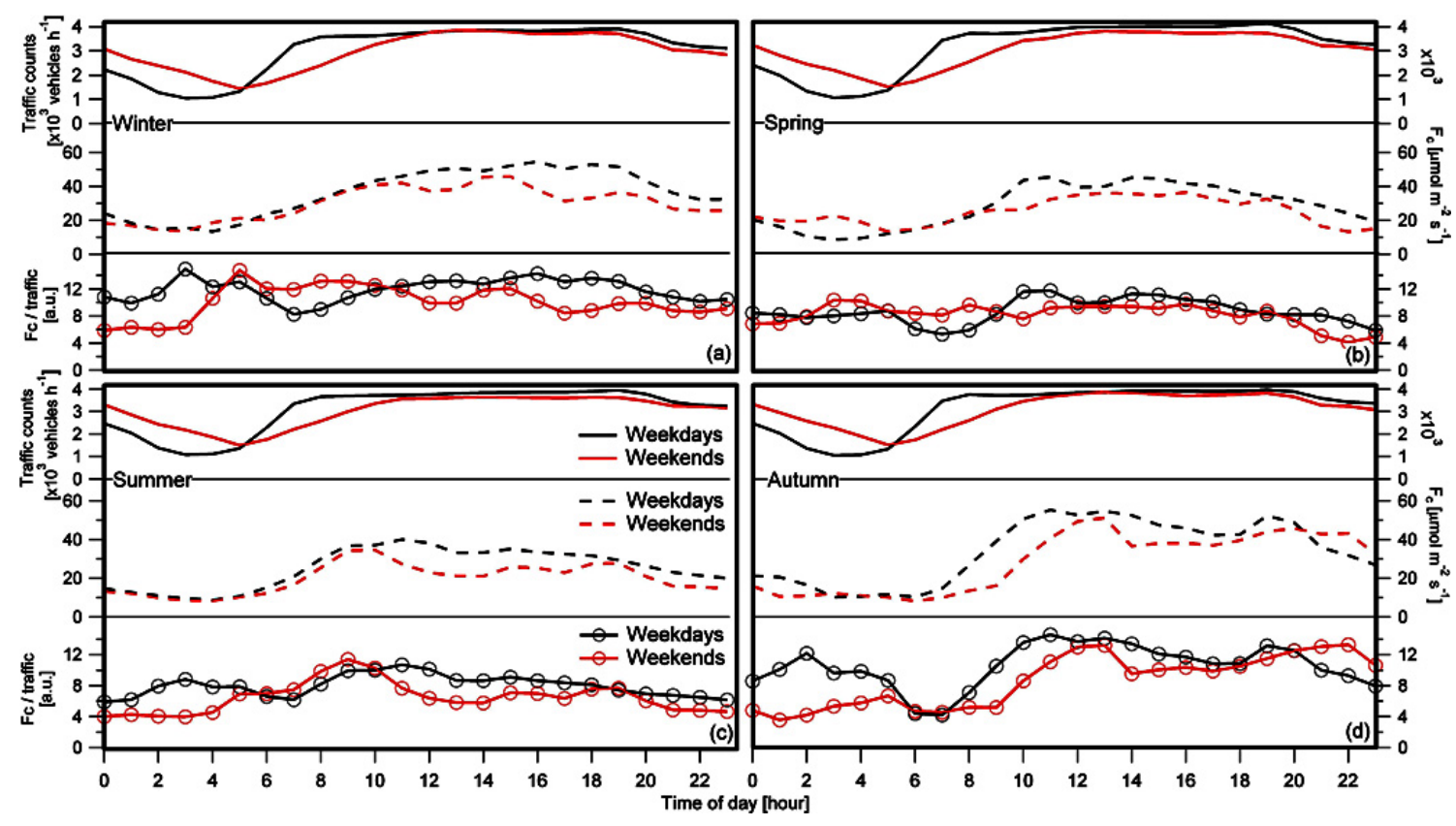

Fig. 9. Weekday-weekend segregation of traffic counts (figures for Marylebone Road used as a proxy for central London), carbon dioxide fluxes measured at the BT Tower and ratio of fluxes to traffic in (a) winter 2007, (b) spring 2007, (c) summer 2007 and (d) autumn 2007.

Table 5. Comparison of observed daytime (09:00-18:00) carbon dioxide fluxes $\left(F_{\mathrm{c}}\right)$ with emissions from natural gas usage, biosphere exchange and human respiration (by season in 2007). The relative contribution from traffic emissions is the difference of $F_{\mathrm{c}}$ and ground sources. Natural gas usage was estimated from third-party data as described in Sect. 2.2 of the Supplement.

\begin{tabular}{lrrrr}
\hline & Winter & Spring & Summer & Autumn \\
\hline Observed $F_{\mathrm{c}}\left[\mathrm{tCO}_{2} \mathrm{~km}^{-2}\right.$ month $\left.^{-1}\right]$ & +4041 & +4802 & +3474 & +4651 \\
Natural gas contribution [\%] & +71.1 & +59.0 & +59.0 & +47.8 \\
Total biosphere exchange [\%] & +1.2 & -2.5 & -4.3 & -1.6 \\
Total human exhalation [\%] & +4.8 & +4.4 & +5.9 & +4.9 \\
Traffic (+oil and coal combustion) [\%] & +22.9 & +39.1 & +39.5 & +48.9 \\
\hline
\end{tabular}

or entrainment from peripheral/ rural areas occurs. However, bottom-up inventory and top-down eddy-covariance figures for $\mathrm{CO}_{2}$ emissions are statistically similar (based on standard deviations of the means) and it can therefore be concluded that the BT tower was an adequate location for monitoring trace gas fluxes in central London and that the KM footprint model provided a reasonable approximation for that site, especially during daytime. This is in line with the observations made by Wood et al. (2010a) that locally-normalised turbulence at high levels above central London is similar to that above rural terrain. This suggests that the measurements are representative of the urban morphology surrounding the site and that advection errors were limited.

\section{Seasonal controls of $\mathrm{CO}_{2}$ emissions}

Measured winter time emissions of $\mathrm{CO}_{2}$ in central London were estimated to have been dominated by natural gas emissions $(71.1 \%)$ whilst traffic and other fossil fuel burning contributed $22.9 \%$ (Table 5). It is important to emphasize that traffic emissions from eddy-covariance measurements were not estimated from traffic counts but taken as the difference between the total eddy-covariance flux and the estimated cumulative contributions from other sources (natural gas, biospheric and human). The NAEI takes fleet composition into account for the purpose of estimating trafficbased emissions of $\mathrm{CO}_{2}{ }^{6}$. Emissions from natural gas combustion reached their lowest point in autumn (47.8\%), when traffic emissions accounted for ca. $48.9 \%$ of the measured

\footnotetext{
${ }^{6}$ http://www.airquality.co.uk/reports/cat07/1010011332 UKMappingMethodReport2007.pdf
} 
Table 6. Annual emissions estimates for six cities, plan area of vegetation and population density around the study areas (see Table 4 for references).

\begin{tabular}{lrrrrrr}
\hline & $\begin{array}{r}\text { London } \\
\text { (this study) }\end{array}$ & Copenhagen & Edinburgh & Melbourne & $\begin{array}{r}\text { Mexico } \\
\text { City }\end{array}$ & Tokyo \\
\hline $\begin{array}{l}\text { Emissions } \\
\left(\mathrm{t} \mathrm{CO}_{2} \mathrm{~km}^{-2} \mathrm{y}^{-1}\right)\end{array}$ & 35500 & 12800 & 36000 & 8490 & 12800 & 12290 \\
\hline $\begin{array}{l}\text { Vegetation } \\
\text { cover }(\%)\end{array}$ & 8 & - & 20 & 38 & 16 & 21 \\
\hline $\begin{array}{l}\text { Population density } \\
\text { (persons km }\end{array}$ & 10000 & - & 7500 & 2940 & 12000 & 11800 \\
\hline
\end{tabular}

flux. These figures reflect not only the seasonal variations of source strengths but crucially also of the position of the footprint. The latter was dominated throughout 2007 by emissions from the City of Westminster (up to $82 \%$ of daytime summer fluxes measured at the tower were attributed to that borough) which is densely populated but also greener than average. The net impact of vegetation during the 2007 growing season was ca. $174 \mathrm{tCO}_{2} \mathrm{~km}^{-2}$ month $^{-1}$ for Westminster (Table S1, Supplement) where green space accounts for ca. $15 \%$ of the plan area (compared to $8 \%$ for London taken as a whole). Data records of first and last annual lawn cuts in central England from 2000 to 2004 were used to define the growing season (mid-March and late October) (Sparks et al., 2005). Assuming leaf-on was complete from early May to mid-September for the species within the tower footprint, the vegetative growth in the borough of Westminster assimilates $\sim 4330 \mathrm{t} \mathrm{CO}_{2}$ or $0.4 \%$ of the annual emissions of carbon dioxide (based on the 2006 NAEI $\mathrm{CO}_{2}$ emissions figure).

For comparison, Nemitz et al. (2002) estimated that gas combustion accounted for $52 \%$ and other fossil fuel combustion sources (dominated by traffic) accounted for $41 \%$ of autumn conditions in central Edinburgh, while the London autumn values of $47.8 \%$ and $48.9 \%$, respectively, reveal a smaller contribution from gas combustion. Annual emissions in central London were comparable to the $10 \mathrm{kt} \mathrm{C} \mathrm{km}^{-2} \mathrm{y}^{-1}$ reported for Edinburgh, but were nearly three times larger than for measurement sites in Tokyo, Mexico City and Copenhagen, and roughly four times higher than in Melbourne (Table 6). This reflects the fact that measurements in London and Edinburgh were conducted above the city centre, rather than residential areas. Annual emissions in London, Mexico City, Tokyo and Melbourne exhibit a correlation with vegetation cover (Fig. 10) but not with population density. Whilst industrial, commercial and domestic fossil fuel usage (e.g. traffic, heating) are the main sources of urban $\mathrm{CO}_{2}$ and are likely to vary between sites due to, e.g., climate, vehicle fleet or land use, Fig. 10 illustrates the combined impact of plant assimilation on urban $\mathrm{CO}_{2}$ emissions.

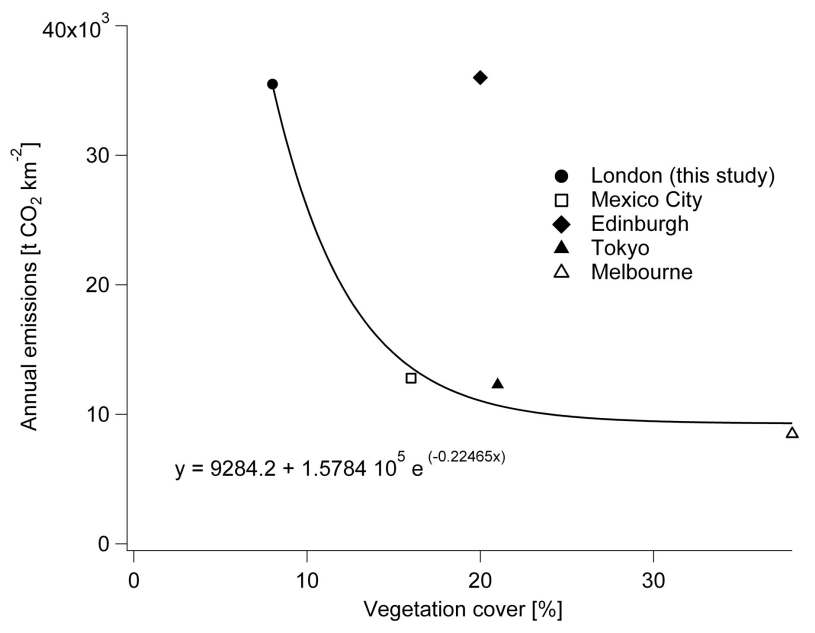

Fig. 10. Annual $\mathrm{CO}_{2}$ emissions in five cities compared with vegetation cover.

\section{Conclusions}

The close agreement between measured fluxes and bottomup emission inventory estimates (within $3 \%$ during daytime) suggests that the $190 \mathrm{~m}$ tall BT Ttower in central London was a suitable measurement site for characterising average emissions during daytime, while some care needs to be taken to interpret night-time fluxes. This would imply that long-term flux measurements can be used to track changes in emissions, and to quantify emissions of pollutants for which urban area sources are more poorly understood and more variable than those of $\mathrm{CO}_{2}$. Measurements for a year reveal that the seasonal dynamics of atmospheric carbon dioxide concentrations are strongly linked to the natural background vegetation cycle, seasonal variations in natural gas consumption (e.g. commercial and domestic heating, referred to as background emissions) and that diurnal trends were regulated by dilution, consistent with cycles of growth and shrinkage of the boundary layer. Diurnal fluxes of $\mathrm{CO}_{2}$ were strongly correlated with traffic counts and, to a lesser extent, with atmospheric stratification in the dominant stability range $(-1.5$ to 
$+2)$. Because traffic correlates with atmospheric stability it is difficult to untangle the two effects. Night-time fluxes were not unequivocally correlated to traffic counts which could be explained by decoupling of the tower from street level and/or dominance by non-traffic sources. Gradient measurements would have provided useful information on the storage term and periods of decoupling from the surface. It is recommended that future flux measurements at such high measurement heights be accompanied with concentration gradient measurements to reduce remaining uncertainties due to storage effects. However, we were able to demonstrate good agreement between the eddy-covariance results and a bottom-up inventory which can be considered as a validation of both approaches as far as daytime averages are concerned. Without gradient data we can only speculate as to the causes of the discrepancies (although not statistically significant) between inventory and eddy-covariance data but there is no indication that the absence of this information had a critical impact on the analysis carried out in this study.

Seasonal variations in heating-related emissions and vegetative assimilation through photosynthesis during the growing season had an impact on $\mathrm{CO}_{2}$ fluxes measured at the tower. Whilst the urban environment of central London was a net source of $\mathrm{CO}_{2}$ in 2007, summer net emissions were $20 \%$ lower than their wintertime counterparts due to the combined effects of a reduction in heating emissions and uptake by photosynthesising plants. Natural gas demand was found to dominate emissions (ca. $71 \%$ ) in winter, whilst a more balanced partitioning, comparable to values reported for Edinburgh by Nemitz et al. (2002), was observed in autumn: $47.8 \%$ of autumn $\mathrm{CO}_{2}$ emissions were attributed to natural gas burning, compared to $48.9 \%$ for traffic. Gross plant assimilation in the central London borough of Westminster - where green spaces account for ca. $15 \%$ of borough surface area compared to ca. $8 \%$ elsewhere - was estimated at $4330 \mathrm{t} \mathrm{CO}_{2} \mathrm{y}^{-1}$, which represents only $0.4 \%$ of the total annual emissions. Grass was estimated to make the largest contribution to net assimilation, with trees being responsible for a mere $5 \%$. These results suggest that the total surface area allocated to green spaces would have to be increased by a factor of 250 in order to neutralise anthropogenic emissions of carbon dioxide in central London. Considering how heavilyurbanised the studied area was in 2007, it seems likely that central London will remain a strong source of $\mathrm{CO}_{2}$ in the foreseeable future.

\section{Supplementary material related to this article is available online at: http://www.atmos-chem-phys.net/11/1913/2011/ acp-11-1913-2011-supplement.pdf.}

Acknowledgements. The authors would like to thank Trevor Blackall (King's College London, KCL), Hongbin Wang (Imperial College London), Vasileios Pappas (KCL), Alastair Reynolds (KCL) and Nathan Sparks (Imperial College London) for their kind help in running the instruments when remote intervention was not possible. We are grateful to BT staff, Dave Maidlow in particular, for access to the site and help with practical aspects surrounding this study. We would also like to thank Parvin Miah (Transport for London) for hourly traffic counts at four counting sites in central London. Finally, the footprint tool was kindly made available by Albrecht Neftel, Agroscope, Zürich, Switzerland. The measurements were supported by the UK Natural Environment Research Council (NERC) through the grant "CityFlux".

Edited by: R. M. Harrison

\section{References}

Allan, J. D., Williams, P. I., Morgan, W. T., Martin, C. L., Flynn, M. J., Lee, J., Nemitz, E., Phillips, G. J., Gallagher, M. W., and Coe, H.: Contributions from transport, solid fuel burning and cooking to primary organic aerosols in two UK cities, Atmos. Chem. Phys., 10, 647-668, doi:10.5194/acp-10-647-2010, 2010.

Aubinet, M., Grelle, A., Ibrom, A., Rannik, U., Moncrieff, J., Foken, T., Kowalski, A. S., Martin, P. H., Berbigier, P., Bernhofer, C., Clement, R., Elbers, J., Granier, A., Grunwald, T., Morgenstern, K., Pilegaard, K., Rebmann, C., Snijders, W., Valentini, R., and Vesala, T.: Estimates of the annual net carbon and water exchange of forests: The EUROFLUX methodology, Adv. Ecol. Res., 30, 113-175, 2000.

Baldocchi, D., Falge, E., Gu, L. H., Olson, R., Hollinger, D., Running, S., Anthoni, P., Bernhofer, C., Davis, K., Evans, R., Fuentes, J., Goldstein, A., Katul, G., Law, B., Lee, X. H., Malhi, Y., Meyers, T., Munger, W., Oechel, W., Paw U, K. T., Pilegaard, K., Schmid, H. P., Valentini, R., Verma, S., Vesala, T., Wilson, K., and Wofsy, S.: FLUXNET: A new tool to study the temporal and spatial variability of ecosystem-scale carbon dioxide, water vapor, and energy flux densities, B. Am. Meteorol. Soc., 82, 2415-2434, 2001.

Barlow, J. F., Dunbar, T. M., Nemitz, E. G., Wood, C. R., Gallagher, M. W., Davies, F., O'Connor, E., and Harrison, R. M.: Boundary layer dynamics over London, UK, as observed using Doppler lidar, Atmos. Chem. Phys. Discuss., 10, 19901-19938, doi:10.5194/acpd-10-19901-2010, 2010.

Buermann, W., Lintner, B. R., Koven, C. D., Angert, A., Pinzon, J. E., Tucker, C. J., and Fung, I. Y.: The changing carbon cycle at Mauna Loa Observatory, P. Natl. Acad. Sci. USA, 104, 42494254, 2007.

Bush, T., Tsagatakis, I., King, K., and Passant, N.: NAEI UK Emission Mapping Methodology 2006, AEAT/ENV/R/2696, available at: http://www.naei.org.uk/reports.php, 2008.

Carslaw, D. and Ropkins, K.: openair: Open-source tools for the analysis of air pollution data, $\mathrm{R}$ package version $0.2-5 / \mathrm{r} 68$, available at: http://R-Forge.R-project.org/projects/openair/, 2010.

Coutts, A. M., Beringer, J., and Tapper, N. J.: Characteristics influencing the variability of urban $\mathrm{CO}_{2}$ fluxes in Melbourne, Australia, Atmos. Environ., 41, 51-62, 2007.

Crawford, B., Grimmond, C. S. B., and Christen, A.: Five years of carbon dioxide fluxes measurements in a highly vegetated suburban area, Atmos. Environ., 45, 896-905, 2011. 
Evans, S.: 3-D cities and numerical weather prediction models: An overview of the methods used in the LUCID project, available at: http://eprints.ucl.ac.uk/17404/1/17404.pdf, UCL, London, 2009.

Foken, T. and Wichura, B.: Tools for quality assessment of surfacebased flux measurements, Agr. Forest Meteorol., 78, 83-1-05, 1996.

Foken, T., Gödecke, M., Mauder, M., Mahrt, L., Amiro, B., and Munger, W.: Post-field data quality control, in: Handbook of micrometeorology, edited by: Lee, X., Kluwer Academic Publishers, 2004.

Grimmond, C. S. B., and Oke, T. R.: Aerodynamic properties of urban areas derived, from analysis of surface form, J. Appl. Meteorol., 38, 1262-1292, 1999.

Grimmond, C. S. B., King, T. S., Cropley, F. D., Nowak, D. J., and Souch, C.: Local-scale fluxes of carbon dioxide in urban environments: methodological challenges and results from Chicago, Environ. Pollut., 116, S243-S254, 2002.

Grimmond, C. S. B., Salmond, J. A., Oke, T. R., Offerle, B., and Lemonsu, A.: Flux and turbulence measurements at a densely built-up site in Marseille: Heat, mass (water and carbon dioxide), and momentum, J. Geophys. Res.-Atmos., 109, D24101, doi:10.1029/2004JD004936, 2004.

Hall, C. A. S., Ekdahl, C. A., and Wartenberg, D. E.: 15-year record of biotic metabolism in northern-hemisphere, Nature, 255, 136138, 1975.

Keeling, C. D., Chin, J. F. S., and Whorf, T. P.: Increased activity of northern vegetation inferred from atmospheric $\mathrm{CO}_{2}$ measurements, Nature, 382, 146-149, 1996.

Kormann, R. and Meixner, F. X.: An analytical footprint model for non-neutral stratification, Bound.-Lay. Meteorol., 99, 207-224, 2001.

Langford, B., Davison, B., Nemitz, E., and Hewitt, C. N.: Mixing ratios and eddy covariance flux measurements of volatile organic compounds from an urban canopy (Manchester, UK), Atmos. Chem. Phys., 9, 1971-1987, doi:10.5194/acp-9-1971-2009, 2009.

Langford, B., Nemitz, E., House, E., Phillips, G. J., Famulari, D., Davison, B., Hopkins, J. R., Lewis, A. C., and Hewitt, C. N.: Fluxes and concentrations of volatile organic compounds above central London, UK, Atmos. Chem. Phys., 10, 627-645, doi:10.5194/acp-10-627-2010, 2010.

Lebaube, S., Le Goff, N., Ottorini, J. M., and Granier, A.: Carbon balance and tree growth in a Fagus sylvatica stand, Ann. For. Sci., 57, 49-61, 2000.

Martin, C. L.: Transportation of Urban Ultrafine Particles in Four European Cities. Ph.D. Thesis, University of Manchester, Manchester, 2009a.

Martin, C. L., Longley, I. D., Dorsey, J. R., Thomas, R. M., Gallagher, M. W., and Nemitz, E.: Ultrafine particle fluxes above four major European cities, Atmos. Environ., 43, 4714-4721, 2009b.

Mayor of London: Connecting Londoners with trees and woodlands, available at: http://www.london.gov.uk/mayor/ environment/forest/docs/ltwf_full.pdf, 2005.

Moncrieff, J., Clement, R., Finnigan, J., and Meyers, T.: Averaging, detrending and filtering of eddy covariance time series, in: Handbook of Micrometeorology, edited by: Lee, X., Kluwer Academic Publishers, 2004.

Moriwaki, R. and Kanda, M.: Seasonal and diurnal fluxes of radia- tion, heat, water vapor, and carbon dioxide over a suburban area, J. Appl. Meteorol., 43, 1700-1710, 2004.

Neftel, A., Spirig, C., and Ammann, C.: Application and test of a simple tool for operational footprint evaluations, Environ. Pollut., 152, 644-652, 2008.

Nemitz, E., Hargreaves, K. J., McDonald, A. G., Dorsey, J. R., and Fowler, D.: Meteorological measurements of the urban heat budget and $\mathrm{CO}_{2}$ emissions on a city scale, Environ. Sci. Technol., 36, 3139-3146, 2002.

Nemitz, E., Phillips, G. J., Di Marco, C. F., Allan, J. D., Barlow, J. F., Coe, H., Thorpe, A., Dall'Osto, M., Harrison, R. M., and Williams, P. I.: Concentrations, gradients and fluxes of inorganic reactive gases and aerosol components above London, Atmos. Chem. Phys. Discuss., in preparation, 2010.

Padhra, A.: Estimating the sensitivity of urban surface drag to building morphology, PhD, University of Reading, Reading, 2009.

Phillips, G. J., Thomas, R., Famulari, D., Williams, P. I., Crosier, J., Allan, J. D., Coe, H., Gallagher, M., Flynn, M., and Nemitz, E.: Fluxes of submicron aerosol components above three UK cities, Atmos. Chem. Phys. Discuss., in preparation, 2010.

R Development Core Team: R: A language and environment for statistical computing, available at: http://www.R-project.org, 2009.

Reid, K. H. and Steyn, D. G.: Diurnal variations of boundary-layer carbon dioxide in a coastal city - Observations and comparison with model results, Atmos. Environ., 31, 3101-3114, 1997.

Rigby, M., Toumi, R., Fisher, R., Lowry, D., and Nisbet, E. G.: First continuous measurements of $\mathrm{CO}_{2}$ mixing ratio in central London using a compact diffusion probe, Atmos. Environ., 42, 8943-8953, 2008.

Roth, M. and Oke, T. R.: Relative efficiencies of turbulent transfer of heat, mass, and momentum over a patchy urban surface, J. Atmos. Sci., 52, 1863-1874, 1995.

Soegaard, H. and Moller-Jensen, L.: Towards a spatial $\mathrm{CO}_{2}$ budget of a metropolitan region based on textural image classification and flux measurements, Remote Sens. Environ., 87, 283-294, 2003.

Sparks, T. H., Croxton, P. J., Collinson, N., and Grisenthwaite, D. A.: The grass is greener (for longer), Weather, 60, 121-125, 2005.

Tans, P., NOAA/ESRL, available at: www.esrl.noaa.gov/gmd/ccgg/ trends/, 2009.

Velasco, E., Pressley, S., Allwine, E., Westberg, H., and Lamb, B.: Measurements of $\mathrm{CO}_{2}$ fluxes from the Mexico City urban landscape, Atmos. Environ., 39, 7433-7446, 2005.

Vesala, T., Jarvi, L., Launiainen, S., Sogachev, A., Rannik, U., Mammarella, I., Siivola, E., Keronen, P., Rinne, J., Riikonen, A., and Nikinmaa, E.: Surface-atmosphere interactions over complex urban terrain in Helsinki, Finland, Tellus B, 60, 188-199, 2008.

Vogt, R., Christen, A., Rotach, M. W., Roth, M., and Satyanarayana, A. N. V.: Temporal dynamics of $\mathrm{CO}_{2}$ fluxes and profiles over a central European city, Theor. Appl. Climatol., 84, 117-126, 2006.

Wood, C. R., Arnold, S. J., Balogun, A. A., Barlow, J. F., Belcher, S. E., Britter, R. E., Cheng, H., Dobre, A., Lingard, J. J. N., Martin, D., Neophytou, M., Petersson, F. K., Robins, A. G., Shallcross, D. E., Smalley, R. J., Tate, J. E., Tomlin, A. S., and White, I. R.: Dispersion experiments in central London: the 2007 DAPPLE project, B. Am. Meteorol. Soc. 90, 955-969, 2009. 